\title{
Article
}

\section{Diet Quality and Dietary Inflammatory Index Score among Women's Cancer Survivors}

\author{
Sibylle Kranz ${ }^{1, *(\mathbb{D})}$, Faten Hasan ${ }^{1}\left(\mathbb{D}\right.$, Erin Kennedy ${ }^{2}$, Jamie Zoellner ${ }^{2}$, Kristin A Guertin ${ }^{2}$, Nitin Shivappa ${ }^{3}$, \\ James R Hébert ${ }^{3}{ }^{1}$, Roger Anderson ${ }^{2}$ and Wendy Cohn ${ }^{2}$
}

check for

updates

Citation: Kranz, S.; Hasan, F.; Kennedy, E.; Zoellner, J.; Guertin, K.A.; Shivappa, N.; Hébert, J.R.; Anderson, R.; Cohn, W. Diet Quality and Dietary Inflammatory Index Score among Women's Cancer Survivors. Int. J. Environ. Res. Public Health 2022, 19, 1916. https://doi.org /10.3390/ijerph19041916

Academic Editor: Paul B. Tchounwou

Received: 11 January 2022

Accepted: 5 February 2022

Published: 9 February 2022

Publisher's Note: MDPI stays neutral with regard to jurisdictional claims in published maps and institutional affiliations.

Copyright: (C) 2022 by the authors. Licensee MDPI, Basel, Switzerland. This article is an open access article distributed under the terms and conditions of the Creative Commons Attribution (CC BY) license (https:// creativecommons.org/licenses/by/ $4.0 /)$.
1 Department of Kinesiology, University of Virginia, Charlottesville, VA 22903, USA; fh4ua@virginia.edu

2 Department of Public Health Sciences, University of Virginia, Charlottesville, VA 22903, USA; emk2fz@virginia.edu (E.K.); jz9q@virginia.edu (J.Z.); kag8c@virginia.edu (K.A.G.); ra2ee@virginia.edu (R.A.); wfc2r@virginia.edu (W.C.)

3 Cancer Prevention and Control Program, Department of Epidemiology and Biostatistics, Arnold School of Public Health, University of South Carolina, Columbia, SC 29208, USA; shivappa@email.sc.edu (N.S.); jhebert@sc.edu (J.R.H.)

* Correspondence: sibylle.kranz@virginia.edu

\begin{abstract}
The purpose of this study was to investigate Healthy Eating Index 2015 (HEI-2015) and Energy-Adjusted Dietary Inflammatory Index (E-DII ${ }^{\mathrm{TM}}$ ) scores in women's cancer survivors and to examine socio-economic (SES) characteristics associated with these two diet indices. In this crosssectional study, survivors of women's cancers completed a demographic questionnaire and up to three 24-h dietary recalls. HEI-2015 and E-DII scores were calculated from average intakes. One-way ANOVA was used to examine the association of various demographic factors on HEI-2015 and E-DII scores. Pearson Correlation was used to calculate the correlation between the two scores. The average HEI-2015 score was $55.0 \pm 13.5$, lower than the national average, and average E-DII was $-1.14 \pm 2.24$ with $29 \%$ of women having a more pro-inflammatory and $71 \%$ a more anti-inflammatory diet. Diets with higher HEI-2015 scores were associated with more anti-inflammatory diets $(\mathrm{r}=-0.67, p<0.001)$. Those having a graduate degree $(\mathrm{F}(2,49)=3.6, p=0.03)$ and completing cancer treatment $>4$ years ago $(\mathrm{F}(2,49)=4.8, p=0.01)$ had higher HEI-2015 scores. There were no associations between SES and E-DII scores. The diet quality of women's cancer survivors is comparatively low, but many achieved an anti-inflammatory diet; a promising avenue for preventing recurrence. There is an urgent need to involve health care professionals in the guidance of women's cancer survivors to improve diet quality and prevent cancer recurrence.
\end{abstract}

Keywords: women's cancer survivors; cancer survivor guidelines; dietary guidance; healthy eating index; dietary inflammatory index

\section{Introduction}

In 2017, women's cancers, including breast, ovarian and other cancers accounted for $41 \%$ of new cancer cases and $26 \%$ of cancer deaths in the United States (U.S.) [1]. The U.S. population has an estimated 16.9 million cancer survivors, a term that refers to a person with a history of cancer, beginning at diagnosis and divided into three phases: (1) time of diagnosis to the end of initial treatment; (2) transition from treatment to extended survival; and (3) long-term survival [2]. Although evidence indicates the role of inflammation in cancer risk [3,4], modifiable lifestyle factors associated with inflammation, such as diet quality [5], are understudied. Available studies on diet, cancer recurrence, and mortality in cancer survivors have shown inconsistent results [6]; however, consumption of a highquality diet is associated with decreased mortality, specifically for those with the highest intake of vegetables and fish [7]. Breast cancer survivors consuming a Mediterranean diet appear to have reduced cancer recurrence and mortality [8]. 
Because consuming a high-quality diet is an important lifestyle factor to reduce morbidity and potentially prevent recurrence of cancer, the diet quality of women's cancer survivors needs to be better understood. The American Cancer Society (ACS) and the World Cancer Research Fund/American Institute for Cancer Research (WCRF/AICR) created diet guidelines for cancer survivors for cancer prevention $[9,10]$. The WCRF/AICR guidelines from the Third Expert Report are part of the Continuous Update Project (CUP) and "is the world's largest, more authoritative and up-to-date source of scientific research on cancer prevention and survivorship through diet, nutrition, physical activity, and cancer" [10]. According to WCRF, the two main parts of their work fall into determining the lifestyle factors that affect cancer and "sharing the evidence with as many people as possible". The WCRF also notes that cancer survivors should follow the recommendations along with the guidance of their health care professionals. The ACS guidelines were based on addressing four areas of individual choices that may reduce cancer risk: weight management, physical activity, diet, and alcohol consumption. Thus, cancer prevention guidelines have shifted to a more comprehensive view by focusing on dietary patterns rather than intake levels of individual nutrients and compounds. The guidelines are based on systematic reviews and CUP provided by WCRF/AICR, as well as more recently published systematic reviews and large pooled analyses. Diet quality emerged as an important factor.

Two different measures of diet quality are the Healthy Eating Index-2015 (HEI2015) [11] and Dietary Inflammatory Index (DII ${ }^{\circledR}$ ), a literature-derived tool to assess the inflammatory potential of diet [12]. While the HEI measures adherence to the current intake levels of food groups used in the Dietary Guidance for Americans, depicted in the MyPlate system, the DII focusses on consumption of dietary components that modulate inflammation, including anti-oxidants. A pro-inflammatory diet (higher DII score) is associated with higher levels of inflammatory biomarkers including C-reactive protein and interleukin-6 [13-16].

To date, much knowledge of dietary intake behavior in cancer patients focuses on the treatment period and research on diet quality in cancer survivors and especially cancer survivors living in rural areas are needed [17]. The purpose of this exploratory study was to (1) describe diet quality, as measured using the HEI-2015 and DII, (2) examine demographic characteristics associated with these two diet indices, and (3) explore the correlation between the HEI-2015 and energy-adjusted DII (E-DII ${ }^{\mathrm{TM}}$ ) in a convenience sample of rural women's cancer survivors.

\section{Materials and Methods}

Approximately three years after a previous women's cancer survivorship study [18], participants who indicated interest in future studies were recruited for this cross-sectional study. Questionnaires were sent to participants to collect information on demographic data (age, education, income, financial security), years since treatment, self-reported height and weight, and weight-loss goals. Rurality status was determined using 5-digit Zip-codes and rural-urban commuting area (RUCA) county characteristics [19].

After consenting to participate in the study, participants completed the questionnaire and provided up to three phone-administered 24-h recalls for two weekdays and one weekend day between April and July 2019. Data were collected by trained interviewers who called participants at their preferred day and time using Nutrient Data System for Research (NDS-R) software [version 2018, Nutrition Coordinating Center (NCC), University of Minnesota, Minneapolis, MN) [20]. Foods not included in the nutrient database were noted and estimated using the most similar available food. Inter-interviewer ratings indicated less than $5 \%$ variation.

The Healthy Eating Index-2015 (HEI-2015), developed by the U.S Department of Agriculture (USDA), measures alignment between an individual's diet and the 2015-2020 USDA Dietary Guidelines [11]. For women who completed more than one dietary recall, nutrients were averaged to reflect their typical diet. Total HEI-2015 scores were calculated 
using the SAS program developed and provided by NDS-R [21] and range from 0-100, with higher scores reflecting better adherence to intake recommendations [22,23].

DII scores were calculated using 28 parameters available from NDS-R (alcohol, vitamin B6 and B12, beta carotene, caffeine, carbohydrates, cholesterol, total fat, fiber, folic acid, iron, magnesium, MUFA, niacin, omega 3, protein, PUFA, riboflavin, saturated fat, selenium, thiamin, trans fat, vitamins A, C, D, and E, and zinc) [12]. Supplements were not included in this study. A higher DII score indicates a more pro-inflammatory diet. To control for the effect of total energy intake, E-DII scores computed per $1000 \mathrm{kcal}$ of food consumed using 27 of the parameters (energy was in the denominator) [24].

Averages with standard deviations, proportions, and frequencies were calculated for each woman to describe the study sample and diet characteristics. Analysis of variance (ANOVA) was performed using RStudio to investigate the relationships among various demographic and lifestyle factors on HEI-2015 and E-DII scores [25]. Potential interactions between related demographic and lifestyle factors, such as education and income, were examined. Finally, the relationship between HEI-2015 and E-DII scores was evaluated using Pearson's correlation coefficient [26]. The data presented in this study are available in Supplementary Table S1.

\section{Results}

A total of 169 questionnaires were mailed to eligible participants. Two women were deceased, one declined, one questionnaire was returned in the mail, and 54 ( $33 \%$ of eligible) women did not respond, resulting in $111(66 \%)$ participants completing the questionnaire. Of these, $84(76 \%)$ expressed interest in completing dietary recalls, though one woman dropped out (cancer recurrence), one requested not to participate, and 30 were unresponsive to three call attempts. Thus, 52 women $(47 \%)$ completed at least one diet recall $(n=35$ provided three, $n=7 \mathrm{two}$, and $n=10$ one day of intake data) for a total of 129 dietary recalls included in these analyses.

On average, participants were $65 \pm 12$ years old; $94 \%$ White; $96 \%$ non-Hispanic; $71 \%$ married; $47 \%$ with graduate education; all had health insurance coverage; $60 \%$ lived in urban residences. Breast cancer was the most common cancer type (56\%), followed by endometrial/uterine $(29 \%)$ and ovarian $(10 \%)$. Prior treatment received for the initial cancer diagnosis included surgery only $(25 \%)$, surgery combined with radiation $(25 \%)$ or chemotherapy $(8 \%)$, or all three treatments combined $(21 \%)$. About two-thirds reported having at least one other pre-existing condition (in addition to cancer), with nearly one-fifth $(19 \%)$ reporting having at least 3 pre-existing conditions. These include high cholesterol $(33 \%)$, high blood pressure (31\%), arthritis $(25 \%)$, depression $(15 \%)$, anxiety $(13 \%)$, diabetes $(8 \%)$, neuropathy $(4 \%)$, and other pre-existing conditions $(15 \%)$. At the time when the dietary recalls were conducted, average time since completion of active cancer treatment was 4.25 years.

Results showed that, on average, participants did not meet the Dietary Guidelines for Americans for fruits, vegetables, seafood and plant protein, and refined carbohydrates (Table 1). Average macronutrient distribution of calories in women was $45.0 \%$ carbs, $16.8 \%$ protein, $35.7 \%$ fats $(12.1 \%$ saturated fats, $12.5 \%$ monounsaturated fats, and $8.2 \%$ polyunsaturated fats,). On average, women consumed 1711.8 kilocalories, $197.9 \mathrm{~g}$ carbohydrates (18.8 g dietary fiber), $70.2 \mathrm{~g}$ protein, and $70.4 \mathrm{~g}$ fats ( $23.7 \mathrm{~g}$ saturated fats, $24.8 \mathrm{~g}$ monounsaturated fats, $16.3 \mathrm{~g}$ polyunsaturated fats). 
Table 1. Mean HEI-2015 total and component scores among women's cancer survivors $(n=52)$.

\begin{tabular}{ccccc}
\hline & Maximum Score & Mean & SD & Range \\
\hline Total Healthy eating index (HEI-2015) & 100.0 & 55.0 & 13.5 & $29.7-84.6$ \\
\hline Total Vegetables & 5.0 & 3.3 & 1.4 & $0.3-5.0$ \\
\hline Greens and Beans & 5.0 & 2.0 & 1.8 & $0.0-5.0$ \\
\hline Total Fruit & 5.0 & 2.3 & 1.6 & $0.0-5.0$ \\
\hline Whole Fruit & 5.0 & 2.7 & 1.9 & $0.0-5.0$ \\
\hline Whole Grains & 10.0 & 3.8 & 3.0 & $0.0-10.0$ \\
\hline Dairy & 10.0 & 5.5 & 2.7 & $0.0-10.0$ \\
\hline Total Protein Foods & 10.0 & 4.4 & 0.9 & $0.7-5.0$ \\
\hline Seafood and Plant Protein & 5.0 & 2.6 & 1.9 & $0.0-5.0$ \\
\hline Fatty Acid Ratio & 10.0 & 4.6 & 3.1 & $0.0-10.0$ \\
\hline Sodium & 10.0 & 4.7 & 2.9 & $0.0-9.4$ \\
\hline Refined Grains & 10.0 & 6.6 & 2.7 & $0.0-10.0$ \\
\hline Added Sugars & 10.0 & 7.5 & 2.4 & $0.0-10.0$ \\
\hline Saturated Fats & 10.0 & 4.9 & 2.8 & $0.0-10.0$ \\
\hline
\end{tabular}

The average HEI-2015 total score was $55.0 \pm 13.5$ and ranged from 29.7 to 84.6 points (median 56.0) and the average E-DII score was $-1.14 \pm 2.24$, ranging from -5.66 to 3.22 (median -1.24).

Women with a graduate degree and women who completed their last active treatment more than four years prior to this study had higher HEI-2015 ( $p=0.009$ and $p=0.01$, respectively; Table 2). None of the socio-economic characteristics included in this study were significantly associated with E-DII scores. There was a significant inverse correlation between HEI-2015 and E-DII, such that higher HEI-2015 scores correlated with lower E-DII (Figure 1, $\mathrm{r}=-0.67, p<0.001$ ).

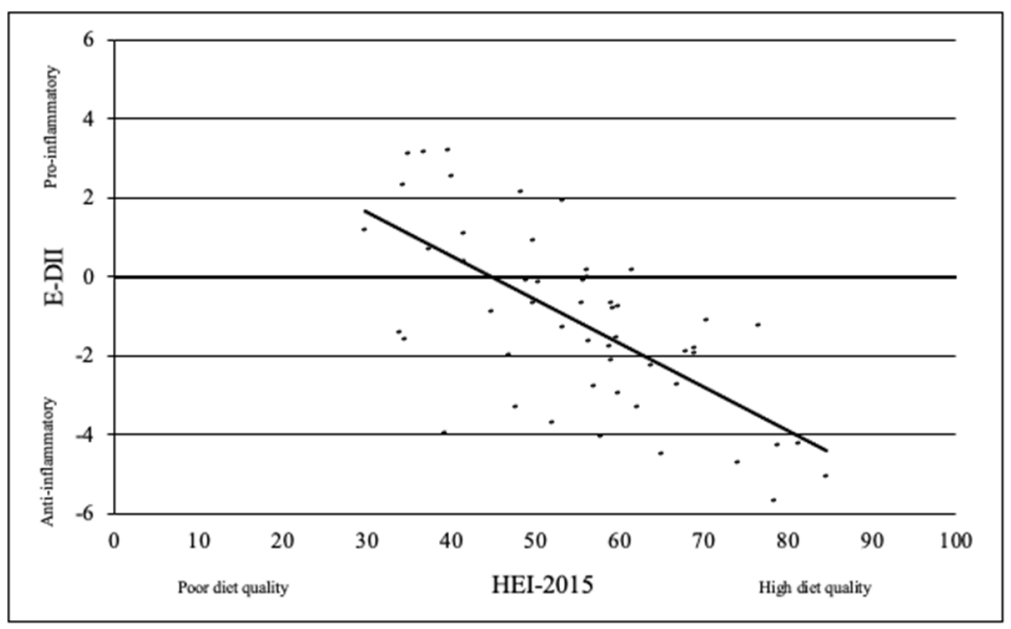

Figure 1. Correlation between Energy-Adjusted Dietary Inflammatory Index (E-DII) scores and Healthy Eating Index (HEI-2015) scores in women's cancer survivors ( $n=52)$. 
Table 2. Diet quality as measured by the Healthy Eating Index (HEI-2015) and Energy-adjusted Dietary Inflammatory Index (E-DII) scores among women's cancer survivors, and differences by demographic characteristics (n 52).

\begin{tabular}{|c|c|c|c|c|c|c|c|c|}
\hline & \multirow[b]{2}{*}{$\mathbf{n}$} & \multirow[b]{2}{*}{$\%$} & \multicolumn{3}{|c|}{ HEI Total Score ${ }^{a}$} & \multicolumn{3}{|c|}{ E-DII $^{a}$} \\
\hline & & & Mean & SD & F-Value & Mean & SD & F-Value \\
\hline Overall Scores & 52 & 100 & 55.0 & 13.5 & & -1.14 & 2.24 & \\
\hline $36-55$ & 9 & 17 & 56.5 & & & -1.17 & & \\
\hline $56-64$ & 16 & 31 & 57.7 & & & -1.76 & & \\
\hline $65-74$ & 15 & 29 & 50.2 & & $\mathrm{~F}(3,48)=0.91$ & -0.72 & & $F(3,48)=0.64$ \\
\hline $75+$ & 12 & 23 & 56.3 & & & -0.84 & & \\
\hline \multicolumn{9}{|c|}{ Education $^{b}$} \\
\hline HS-4yr college & 31 & 60 & 51.1 & & & -0.81 & & \\
\hline Masters-PhD & 21 & 40 & 60.9 & & $\mathrm{~F}(1,50)=7.4^{*}$ & -1.64 & & $F(1,50)=1.73$ \\
\hline \multicolumn{9}{|c|}{ Income } \\
\hline$\$ 0-35 \mathrm{k}$ & 14 & 27 & 55.2 & & & -1.50 & & \\
\hline$\$ 35-75 \mathrm{k}$ & 14 & 27 & 49.3 & & & -0.23 & & \\
\hline$\$ 75 \mathrm{k}+$ & 20 & 38 & 58.2 & & $\mathrm{~F}(2,45)=1.73$ & -1.45 & & $\mathrm{~F}(2,45)=1.49$ \\
\hline Not reported & 4 & 8 & & & & & & \\
\hline Living comfortably & 30 & 58 & 56.0 & & & -1.07 & & \\
\hline $\begin{array}{l}\text { Other (getting by on present income, finding it difficult on } \\
\text { present income, and finding it very difficult on present } \\
\text { income) }\end{array}$ & 22 & 42 & 53.7 & & $F(1,50)=0.35$ & -1.24 & & $F(1,50)=0.07$ \\
\hline \multicolumn{9}{|c|}{ Rurality } \\
\hline Urban & 31 & 60 & 56.1 & & & -1.39 & & \\
\hline Rural & 21 & 40 & 53.4 & & $\mathrm{~F}(1,50)=0.49$ & -0.78 & & $F(1,50)=0.95$ \\
\hline \multicolumn{9}{|c|}{ Years since treatment $^{c}$} \\
\hline $3-4$ years & 20 & 38 & 48.2 & & & -0.44 & & \\
\hline $4-5$ years & 25 & 48 & 59.2 & & $\mathrm{~F}(2,49)=4.8^{* *}$ & -1.67 & & $\mathrm{~F}(2,49)=1.75$ \\
\hline$>5$ years & 7 & 13 & 59.9 & & & -1.29 & & \\
\hline
\end{tabular}


Table 2. Cont.

HEI Total Score ${ }^{\text {a }}$

E-DII $^{\text {a }}$

Body mass index (BMI)

\begin{tabular}{|c|c|c|c|c|c|c|}
\hline \multicolumn{7}{|c|}{ Body mass index (BMI) } \\
\hline$<24$ & 12 & 23 & 57.0 & & -0.84 & \\
\hline 25 to $<30$ & 18 & 35 & 58.1 & & -2.11 & \\
\hline 30 to $<40$ & 16 & 31 & 52.7 & $\mathrm{~F}(3,48)=1.11$ & -0.37 & $F(3,48)=1.96$ \\
\hline$>40$ & 6 & 12 & 48.0 & & -0.93 & \\
\hline \multicolumn{7}{|c|}{ Weight-loss goals } \\
\hline Lose weight & 39 & 75 & 56.1 & \multirow{2}{*}{$\mathrm{F}(1,50)=0.95$} & -1.26 & \multirow{2}{*}{$\mathrm{F}(1,50)=0.41$} \\
\hline Maintain/gain & 13 & 25 & 51.9 & & -0.80 & \\
\hline
\end{tabular}

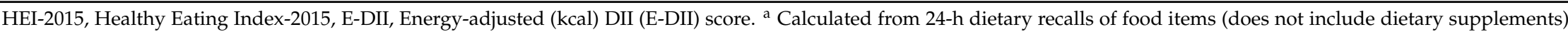
${ }^{\mathrm{b}}$ HEI-2015 for "> graduate" is significantly greater than "HS-college". ${ }^{\mathrm{c}} \mathrm{HEI}-2015$ for " $4-5$ years" and " $>5$ years" both significantly greater than " $<4$ years". ${ }^{*} p<0.05,{ }^{* *} p<0.01$. 


\section{Discussion}

This study was conducted to assess the diet quality and, consequently, the potential risk for cancer recurrence and morbidity in women's cancer survivors. Surprising results included that the average HEI-2015 total score was only 55.0 of possible 100 points and had a wide range ( 29.7 to 84.6 points), which indicates a lower diet quality than the United States national average of 59 points [27]. These findings are in line with others reporting low diet quality in cancer survivors [28,29].

Participants' E-DII scores also indicate reason for concern, as $29 \%$ of women's cancer survivors had a pro-inflammatory diet. Inflammation is the substrate underlying many mechanisms contributing to several types of cancer $[9,10]$ and growing evidence supports the role of diet in inflammatory pathways in both carcinogenesis and disease recurrence. In addition, higher DII/E-DII scores are correlated with increased inflammatory markers $[24,30]$, increased risk of cardiovascular disease and metabolic syndrome [24,31], and $75 \%$ increased mortality for breast, colorectal and lung cancers [32,33], but not endometrial cancer, except in those who are very obese [31]. Thus, women's cancer survivors might considerably reduce the risk of cancer recurrence, if they could achieve a more anti-inflammatory diet.

Considering the impact of diet on cancer risk, it appears that women's cancer survivors do not receive consistently appropriate information on how to achieve a higher quality diet to support health and prevent the future development of cancer or cancer relapse. Thus, there is a need for better dietary guidance for cancer patients. Effective communication of diet quality goals and offers of support for cancer survivors may be needed to achieve these goals.

Only two socio-economic characteristics, education and years since treatment, were associated with HEI-2015 scores, yet these characteristics were not significantly associated with E-DII scores. No interactions were found between related characteristics. Although age, education, BMI, and income are established correlates of diet quality in the general population [34-36] and amongst cancer survivors [28], we did not observe that relationship. However, the participants in this study were considerably younger $(65.0 \pm 12.0$ years vs. $57.6 \pm 10.1)$ and most were White and financially secure compared to the population studied by Springfield et al. [28]. Furthermore, we included other women's cancers (in addition to breast) that tend to have poorer prognoses (e.g., ovarian), compared to a study population that included only breast cancer survivors.

As expected, there was a significant inverse correlation between HEI-2015 and E-DII, which is consistent with other research [37]. This is a significant finding, especially in women's cancer survivors, who may be at risk for recurrence of cancer. As HEI-2015 scores increased, DII scores decreased, indicating better diet quality and lower inflammatory diet patterns. Most importantly, this result shows that guidance and support to achieve and maintain high diet quality and anti-inflammatory diet patterns is critical. Currently, dietary guidelines for cancer survivors are to follow those for cancer prevention $[9,10]$. In general, the existing guidelines for cancer survivors do not differ greatly from those for the general population, despite potentially different nutritional needs. The WCRF/AICR Recommendations for Cancer Survivors are less specific than both ACS and HEI-2015 guidelines. The WCRF/AICR guidelines state to "be healthy weight, be physically active, eat more whole grains, vegetables, fruits and legumes (such as beans), avoid sugary drinks, limit consumption of "fast foods" and other processed foods high in fat, starches, or sugars, limit red meat consumption, and avoid processed meats and alcohol.". Furthermore, guidelines state that "Foods containing fiber and soy decrease mortality risk before and $\geq 12$ months after diagnosis, while total fat and saturated fat increase mortality risk before diagnosis." These guidelines overlap with the HEI-2015 guideline's recommendation to moderate added sugar intake to $\leq 6 \%$ of total energy, moderate saturated fat intake to $\leq 8 \%$ of total energy and consume $\geq 1.5 \mathrm{oz}$ eq of whole grains per $1000 \mathrm{kcal}$. The ACS guidelines overlap with HEI-2015 guidelines in 10 of the 13 components, though only the recommendation to "Eat at least 2.5 cups of vegetables and fruits each day" provides a 
quantified guideline. In the remaining seven areas of overlap with the HEI-2015 guidelines, the ACS guidelines suggest to "limit ...", "avoid ..." ", "minimize ..." , and "choose ... instead of ...". The HEI-2015 components not addressed by the ACS guidelines are recommendations on dairy consumption, total protein foods, and sodium. Furthermore, the ACS guidelines suggest "No more than 2 alcoholic drinks per day for men or 1 drink per day for women", while the HEI-2015 guidelines do not address alcohol. However, breast cancer survivors recently received a more tailored set of recommendations by the ACS based on a systematic literature review conducted in 2015. These guidelines emphasize the importance of consuming a diet high in vegetables, fruits, whole grains, and legumes, while limiting saturated fats and alcohol. Specifically, the guidelines state that "dietary changes sufficient to result in weight loss may be needed to favorably impact breast cancer recurrence and prognosis" [38].

Dietary guidelines are particularly important with respect to body weight management due to the established link between obesity and other comorbidities and cancer survival and recurrence. Specifically, meta-analyses have uncovered associations between BMI status at endometrial cancer diagnosis and cancer recurrence and all-cause mortality [39]. While BMI was not associated with cancer-specific mortality in this study, a relationship was observed between visceral fat and cancer-specific mortality in two of the studies included in the meta-analysis $[40,41]$. This is extraordinarily important because the effect of obesity is mediated nearly exclusively by adipose tissue. So, while there is a strong positive correlation between obesity and adiposity, it is the latter that is the most important in terms of modulating inflammation [42,43]. A meta-analysis by Secord et al. [44] found that endometrial cancer patients with BMI $>40$ had an odds ratio for all-cause mortality of 1.66 compared to women with BMI $<25$. However, the study did not distinguish between all-cause mortality and cancer-specific mortality in this study, and it is well established that obesity alone increases mortality risk [45]. Nonetheless, obesity in endometrial cancer survivors is also associated with poorer quality of life, particularly regarding physical and social functioning [46,47]. These obesity-based results are consistent with the adiposity result in the meta-analyses $[40,41]$ in that it is clear that individuals who are morbidly obese carry massive amounts of adipose tissue. Interestingly, there is a more well-established relationship between BMI and cancer recurrence for breast cancer patients. Obese breast cancer patients, relative to normal-weight patients, had increased risk of cancer recurrence and cancer-specific mortality $(12.2 \%$ and $6.9 \%$, respectively), but no association between weight status and all-cause mortality $[48,49]$. Additionally, weight gain after breast cancer diagnosis, especially in the form of adipose tissue, was also associated with increased all-cause mortality and recurrence [50], particularly if individuals gain greater than $10 \%$ of their body weight $[51,52]$. Unfortunately, weight gain is very common following cancer diagnosis, independent of the treatment used, particularly in those who already have an elevated BMI [53]. Furthermore, weight gain is generally even greater in those who receive adjuvant chemotherapy $[53,54]$, and leaves cancer survivors at an increased risk of cancer recurrence and development of comorbid conditions [55].

Other conditions, such as diabetes, dyslipidemia, and having three or more metabolic comorbidities were all associated with increased risk of developing recurrent breast cancer [56]. Similarly, a Danish breast cancer study found that having any comorbidity was associated with increased all-cause mortality, while only certain comorbidities such as dementia, chronic pulmonary disease, peripheral vascular disease, and liver and renal diseases were associated with increased risk of cancer-specific mortality. This risk was even greater if the comorbidity was diagnosed within 5 years of cancer diagnosis, as opposed to more than 5 years since diagnosis [57]. A similar study in Shanghai found that diabetes and history of stroke were associated with an increased risk of all-cause and non-breast cancer mortality, respectively [58].

Thus, these associations between BMI, comorbidities, and cancer outcomes highlight the importance of lifestyle interventions in cancer patients and cancer survivors. While dietary interventions have shown promising results for improving anti-inflammatory 
nature of the diets of cancer survivors, measures are needed to extend this information to the general population of cancer survivors [59].

More data describing diet quality among cancer survivors, including rural populations, are needed to understand biologic mechanisms that may underlie the associations between diet and survivorship outcomes, tailor guidelines, and design and implement dietary interventions. More specific guidelines would allow healthcare professionals to provide specific, evidence-based oncology nutrition services, such as nutrition education, counseling, and medical nutrition therapy (MNT) [60,61].

Limitations of this study include the use of dietary self-reports, which rely on memory and have the potential for under-reporting of foods-a recognized caveat in nutrition research $[62,63]$. This study also did not measure gastrointestinal symptoms common during cancer treatment, such as nausea, vomiting, dry-mouth, constipation, changes in taste and loss of appetite, all of which may impact diet $[64,65]$; though it must be noted that all women included in this study had completed treatment at least 3 years prior to the dietary recalls. Future studies including the long-term effects of cancer treatment on GI function might elucidate the potential for long-term adverse effects affecting the potential for consuming a high-quality diet. Additionally, representativeness of our study sample and generalizability to other women's cancer survivors should be considered with interpreting and applying these findings. Our study included a relatively small sample of largely White and highly educated women. Additionally, self-selection into the study may reflect underlying sample biases, such as over representation of those with an interest in diet.

Despite these limitations, this exploratory study addresses an important gap in cancer survivorship research. Our study included a high percentage of women living in rural areas $(40 \%)$, an understudied population in the field. Future studies with larger and more diverse samples (i.e., race/ethnicity, SES, rural/urban, different cancer types) are needed to better understand: (1) diet quality among women's cancer survivors; (2) predictors of diet quality; and (3) relationships among diet quality and survival time, quality of life, and inflammatory biomarkers (CRP, IL-6, etc.).

\section{Conclusions}

Overall, our study indicates the need to promote improvements in diet quality among women's cancer survivors. Consuming a diet that meets the Dietary Guidelines for Americans will also likely result in a more anti-inflammatory diet, potentially helping to prevent cancer development or recurrence. Healthcare professionals may be critical partners in efforts to achieve higher HEI-2015 and lower E-DII scores to help protect from cancer recurrences. The need for more specific dietary guidance for women's cancer survivors should be further explored.

Supplementary Materials: The following supporting information can be downloaded at: https: / / www.mdpi.com/article/10.3390/ijerph19041916/s1, Table S1: Diet Quality and Dietary Inflammatory Index Score among Women's Cancer Survivors.

Author Contributions: Conceptualization, S.K., W.C., J.Z. and R.A.; methodology, S.K., W.C. and J.Z.; software, N.S., J.R.H. and F.H.; validation, S.K., W.C., J.Z. and K.A.G.; formal analysis, F.H.; investigation, E.K.; resources, R.A.; data curation, E.K.; writing-original draft preparation, F.H.; writing-review and editing, S.K.; visualization, F.H.; supervision, S.K.; project administration, E.K.; funding acquisition, W.C. All authors have read and agreed to the published version of the manuscript.

Funding: This research was supported by the University of Virginia Cancer Center Support Grant, National Institutes of Health, National Cancer Institute (CA044579).

Institutional Review Board Statement: The study was conducted according to the guidelines of the Declaration of Helsinki, and approved by the Institutional Review Board of The University of Virginia (HSR21007).

Informed Consent Statement: Informed consent was obtained from all subjects involved in the study. 
Data Availability Statement: Please contact the authors to request the data supporting this publication is available from the authors.

Acknowledgments: We thank the women who agreed to participate in this study.

Conflicts of Interest: J.R.H. owns controlling interest in Connecting Health Innovations LLC (CHI), a company that has licensed the right to his invention of the dietary inflammatory index $\left(\mathrm{DII}{ }^{\circledR}\right)$ from the University of South Carolina in order to develop computer and smart phone applications for patient counseling and dietary intervention in clinical settings. Nitin Shivappa is an employee of CHI. The subject matter of this paper will not have any direct bearing on that work, nor has that activity exerted any influence on this project.

\section{References}

1. US Cancer Statistics Working Group. Cancer Statistics Data Visualizations Tool, Based on 2019 Submission Data (1999-2017); U.S. Department of Health and Human Services, Centers for Disease Control and Prevention and National Cancer Institute. 2020. Available online: https:/ / www.cdc.gov/cancer/dataviz/ (accessed on 26 January 2021).

2. American Cancer Society. Cancer Treatment \& Survivorship Facts \& Figures 2019-2021; American Cancer Society: Atlanta, GA, USA, 2019.

3. Pierce, B.L.; Ballard-Barbash, R.; Bernstein, L.; Baumgartner, R.N.; Neuhouser, M.L.; Wener, M.H.; Baumgartner, K.B.; Gilliland, F.D.; Sorensen, B.E.; McTiernan, A.; et al. Elevated Biomarkers of Inflammation Are Associated with Reduced Survival Among Breast Cancer Patients. J. Clin. Oncol. 2009, 27, 3437-3444. [CrossRef] [PubMed]

4. Villasenor, A.; Flatt, S.W.; Marinac, C.; Natarajan, L.; Pierce, J.P.; Patterson, R.E. Postdiagnosis C-Reactive Protein and Breast Cancer Survivorship: Findings from the WHEL Study. Cancer Epidemiol. Biomark. Prev. 2014, 23, 189-199. [CrossRef] [PubMed]

5. Galland, L. Diet and inflammation. Nutr. Clin. Pract. 2010, 25, 634-640. [CrossRef] [PubMed]

6. Kim, N.-H.; Song, S.; Jung, S.-Y.; Lee, E.; Kim, Z.; Moon, H.-G.; Noh, D.-Y.; Lee, J.E. Dietary pattern and health-related quality of life among breast cancer survivors. BMC Women's Health 2018, 18, 65-75. [CrossRef]

7. Schwedhelm, C.; Boeing, H.; Hoffmann, G.; Aleksandrova, K.; Schwingshackl, L. Effect of diet on mortality and cancer recurrence among cancer survivors: A systematic review and meta-analysis of cohort studies. Nutr. Rev. 2016, 74, 737-748. [CrossRef]

8. De Cicco, P.; Catani, M.V.; Gasperi, V.; Sibilano, M.; Quaglietta, M.; Savini, I. Nutrition and Breast Cancer: A Literature Review on Prevention, Treatment and Recurrence. Nutrients 2019, 11, 1514. [CrossRef]

9. $\quad$ Rock, C.L.; Thomson, C.; Gansler, T.; Gapstur, S.M.; McCullough, M.L.; Patel, A.V.; Andrews, K.S.; Bandera, E.V.; Spees, C.K.; Robien, K.; et al. American Cancer Society guideline for diet and physical activity for cancer prevention. CA Cancer J. Clin. 2020, 70, 245-271. [CrossRef]

10. World Cancer Research Fund/American Institute for Cancer Research. Recommendations and Public Health and Policy Implications. 2018. Available online: https:/ /www.wcrf.org/wp-content/uploads/2021/01/Recommendations.pdf (accessed on 14 October 2020).

11. Krebs-Smith, S.M.; Pannucci, T.E.; Subar, A.F.; Kirkpatrick, S.I.; Lerman, J.L.; Tooze, J.A.; Wilson, M.M.; Reedy, J. Update of the Healthy Eating Index: HEI-2015. J. Acad. Nutr. Diet. 2018, 118, 1591-1602. [CrossRef]

12. Shivappa, N.; Steck, S.E.; Hurley, T.G.; Hussey, J.R.; Hébert, J.R. Designing and developing a literature-derived, population-based dietary inflammatory index. Public Health Nutr. 2014, 17, 1689-1696. [CrossRef]

13. Shivappa, N.; Steck, S.E.; Hurley, T.G.; Hussey, J.R.; Ma, Y.; Ockene, I.S.; Tabung, F.; Hébert, J.R. A population-based dietary inflammatory index predicts levels of C-reactive protein in the Seasonal Variation of Blood Cholesterol Study (SEASONS). Public Health Nutr. 2014, 17, 1825-1833. [CrossRef]

14. Shivappa, N.; Hébert, J.R.; Rietzschel, E.R.; De Buyzere, M.L.; Langlois, M.; Debruyne, E.; Marcos, A.; Huybrechts, I. Associations between dietary inflammatory index and inflammatory markers in the Asklepios Study. Br. J. Nutr. 2015, 113, 665-671. [CrossRef] [PubMed]

15. Tabung, F.K.; Steck, S.E.; Zhang, J.; Ma, Y.; Liese, A.D.; Agalliu, I.; Hingle, M.; Hou, L.; Hurley, T.G.; Jiao, L.; et al. Construct validation of the dietary inflammatory index among postmenopausal women. Ann. Epidemiol. 2015, 25, 398-405. [CrossRef] [PubMed]

16. Wirth, M.D.; Shivappa, N.; Davis, L.; Hurley, T.G.; Ortaglia, A.; Drayton, R.; Blair, S.N.; Hébert, J.R. Construct Validation of the Dietary Inflammatory Index among African Americans. J. Nutr. Health Aging 2017, 21, 487-491. [CrossRef] [PubMed]

17. Blake, K.D.; Moss, J.L.; Gaysynsky, A.; Srinivasan, S.; Croyle, R.T. Making the Case for Investment in Rural Cancer Control: An Analysis of Rural Cancer Incidence, Mortality, and Funding Trends. Cancer Epidemiol. Biomark. Prev. 2017, 26, 992-997. [CrossRef] [PubMed]

18. Anderson, R.T.; Eton, D.T.; Camacho, F.T.; Kennedy, E.M.; Brenin, C.M.; DeGuzman, P.B.; Carter, K.F.; Guterbock, T.; Ruddy, K.J.; Cohn, W.F. Impact of comorbidities and treatment burden on general well-being among women's cancer survivors. J. Patient-Rep. Outcomes 2021, 5, 2-14. [CrossRef]

19. U.S. Department of Agriculture Economic Research Service. Rural-Urban Commuting Area Codes. 2020. Available online: https:/ / www.ers.usda.gov / data-products/rural-urban-commuting-area-codes.aspx (accessed on 22 March 2021). 
20. Schakel, S.F.; Sievert, Y.A.; Buzzard, I.M. Sources of data for developing and maintaining a nutrient database. J. Am. Diet Assoc. 1988, 88, 1268-1271. [CrossRef]

21. Nutrition Coordinating Center. Healthy Eating Index (HEI). Available online: http:/ / www.ncc.umn.edu/healthy-eating-indexhei/\#: :text=The\%20Healthy\%20Eating\%20Index\%20(HEI, the\%20Dietary\%20Guidelines\%20for\%20Americans (accessed on 1 December 2020).

22. Reedy, J.; Lerman, J.L.; Krebs-Smith, S.M.; Kirkpatrick, S.I.; Pannucci, T.E.; Wilson, M.M.; Subar, A.F.; Kahle, L.L.; Tooze, J.A. Evaluation of the Healthy Eating Index-2015. J. Acad. Nutr. Diet. 2018, 118, 1622-1633. [CrossRef]

23. Hiza, H.A.B.; Koegel, K.L.; Pannucci, T.E. Diet Quality: The Key to Healthy Eating. J. Acad. Nutr. Diet. 2018, 118, 1622-1633. [CrossRef]

24. Phillips, C.; Shivappa, N.; Hébert, J.; Perry, I. Dietary Inflammatory Index and Biomarkers of Lipoprotein Metabolism, Inflammation and Glucose Homeostasis in Adults. Nutrients 2018, 10, 1033. [CrossRef]

25. Bruce, P.; Bruce, A. Statistical Machine Learning in Practical Statistics for Data Scientists; O’Reilly Media Inc.: Newton, MA, USA, 2017.

26. Pearson's Correlation Coefficient. Encyclopedia of Public Health; Kirch, W., Ed.; Springer: Dordrecht, The Netherlands, 2008; pp. 1090-1091.

27. U.S Department of Agriculture Food and Nutrition Service. Healthy-Eating Index-2015 Data Tables. 2020. Available online: https:/ / www.fns.usda.gov/healthy-eating-index-hei (accessed on 18 March 2021).

28. Springfield, S.; Odoms-Young, A.; Tussing-Humphreys, L.; Freels, S.; Stolley, M. Adherence to American Cancer Society and American Institute of Cancer Research dietary guidelines in overweight African American breast cancer survivors. J. Cancer Surviv. 2019, 13, 257-268. [CrossRef]

29. Kaledkiewicz, E.; Szostak-Wegierek, D. Dietary practices and nutritional status in survivors of breast cancer. Rocz. Panstw. Zakl. Hig. 2018, 69, 175-182. [PubMed]

30. Shivappa, N.; Hebert, J.R.; Marcos, A.; Diaz, L.-E.; Gomez, S.; Nova, E.; Michels, N.; Arouca, A.; González-Gil, E.; Frederic, G.; et al. Association between dietary inflammatory index and inflammatory markers in the HELENA study. Mol. Nutr. Food Res. 2017, 61, 1600707. [CrossRef] [PubMed]

31. Nagle, C.M.; Ibiebele, T.; Shivappa, N.; Hébert, J.R.; Spurdle, A.B.; Webb, P.M.; The Australian National Endometrial Cancer Study Group. Dietary inflammatory index, risk and survival among women with endometrial cancer. Cancer Causes Control 2020, 31, 203-207. [CrossRef] [PubMed]

32. Shivappa, N.; Godos, J.; Hébert, J.; Wirth, M.; Piuri, G.; Speciani, A.; Grosso, G. Dietary Inflammatory Index and Colorectal Cancer Risk-A Meta-Analysis. Nutrients 2017, 9, 1043. [CrossRef] [PubMed]

33. Fowler, M.E.; Akinyemiju, T.F. Meta-Analysis of the association between dietary inflammatory index (DII) and cancer outcomes. Int. J. Cancer 2017, 141, 2215-2227. [CrossRef]

34. Hiza, H.A.; Casavale, K.O.; Guenther, P.M.; Davis, C.A. Diet quality of Americans differs by age, sex, race/ethnicity, income, and education level. J. Acad. Nutr. Diet. 2013, 113, 297-306. [CrossRef]

35. Darmon, N.; Drewnowski, A. Does social class predict diet quality? Am. J. Clin. Nutr. 2008, 87, 1107-1117. [CrossRef]

36. Darmon, N.; Drewnowski, A. Contribution of food prices and diet cost to socioeconomic disparities in diet quality and health: A systematic review and analysis. Nutr. Rev. 2015, 73, 643-660. [CrossRef]

37. Wirth, M.D.; Hébert, J.R.; Shivappa, N.; Hand, G.A.; Hurley, T.G.; Drenowatz, C.; McMahon, D.; Shook, R.P.; Blair, S.N. Antiinflammatory Dietary Inflammatory Index scores are associated with healthier scores on other dietary indices. Nutr. Res. 2016, 36, 214-219. [CrossRef]

38. Runowicz, C.D.; Leach, C.R.; Henry, N.L.; Henry, K.S.; Mackey, H.T.; Cowens-Alvarado, R.L.; Cannady, R.S.; Pratt-Chapman, M.L.; Edge, S.B.; Jacobs, L.A.; et al. American Cancer Society/American Society of Clinical Oncology Breast Cancer Survivorship Care Guideline. CA Cancer J. Clin. 2016, 66, 43-73. [CrossRef]

39. American College of Surgeons Commission on Cancer. Optimal Resources for Cancer Care (2020 Standards); American College of Surgeons Commission on Cancer: Chicago, IL, USA, 2020.

40. Thompson, K.L.; Elliott, L.; Fuchs-Tarlovsky, V.; Levin, R.M.; Voss, A.C.; Piemonte, T. Oncology Evidence-Based Nutrition Practice Guideline for Adults. J. Acad. Nutr. Diet. 2017, 117, 297-310.e247. [CrossRef]

41. Kokts-Porietis, R.L.; Elmrayed, S.; Brenner, D.R.; Friedenreich, C.M. Obesity and mortality among endometrial cancer survivors: A systematic review and meta-analysis. Obes. Rev. 2021, 22, e13337. [CrossRef]

42. Mauland, K.K.; Eng, Ø.; Ytre-Hauge, S.; Tangen, I.L.; Berg, A.; Salvesen, H.B.; Salvesen, Ø.O.; Krakstad, C.; Trovik, J.; Hoivik, E.A.; et al. High visceral fat percentage is associated with poor outcome in endometrial cancer. Oncotarget 2017, 8, 105184-105195. [CrossRef]

43. Celik, E.; Kizildag Yirgin, I.; Goksever Celik, H.; Engin, G.; Sozen, H.; Ak, N.; Saip, P.; Onder, S.; Topuz, S.; Salihoglu, M.Y. Does visceral adiposity have an effect on the survival outcomes of the patients with endometrial cancer? J. Obstet. Gynaecol. Res. 2021, 47, 560-569. [CrossRef]

44. Lozano, C.P.; Wilkens, L.R.; Shvetsov, Y.B.; Maskarinec, G.; Park, S.-Y.; Shepherd, J.A.; Boushey, C.J.; Hebert, J.R.; Wirth, M.D.; Ernst, T.; et al. Associations of the Dietary Inflammatory Index with total adiposity and ectopic fat through the gut microbiota, lipopolysaccharides, and C-reactive protein in the Multiethnic Cohort-Adiposity Phenotype Study. Am. J. Clin. Nutr. 2021, 00, 1-13. [CrossRef] 
45. Lee, Y.S.; Olefsky, J. Chronic tissue inflammation and metabolic disease. Genes Dev. 2021, 35, 307-328. [CrossRef] [PubMed]

46. Secord, A.A.; Hasselblad, V.; Von Gruenigen, V.E.; Gehrig, P.A.; Modesitt, S.C.; Bae-Jump, V.; Havrilesky, L.J. Body mass index and mortality in endometrial cancer: A systematic review and meta-analysis. Gynecol. Oncol. 2016, 140, 184-190. [CrossRef] [PubMed]

47. Bhaskaran, K.; Dos-Santos-Silva, I.; Leon, D.A.; Douglas, I.J.; Smeeth, L. Association of BMI with overall and cause-specific mortality: A population-based cohort study of 3.6 million adults in the UK. Lancet Diabetes Endocrinol. 2018, 6, 944-953. [CrossRef]

48. Smits, A.; Lopes, A.; Bekkers, R.; Galaal, K. Body mass index and the quality of life of endometrial cancer survivors-a systematic review and meta-analysis. Gynecol. Oncol. 2015, 137, 180-187. [CrossRef] [PubMed]

49. Sheng, J.Y.; Sharma, D.; Jerome, G.; Santa-Maria, C.A. Obese Breast Cancer Patients and Survivors: Management Considerations. Oncology 2018, 32, 410-417.

50. Kamineni, A.; Anderson, M.L.; White, E.; Taplin, S.H.; Porter, P.; Ballard-Barbash, R.; Malone, K.; Buist, D.S. Body mass index, tumor characteristics, and prognosis following diagnosis of early-stage breast cancer in a mammographically screened population. Cancer Causes Control 2013, 24, 305-312. [CrossRef] [PubMed]

51. Chan, A.W.; Altman, D.G. Identifying outcome reporting bias in randomised trials on PubMed: Review of publications and survey of authors. BMJ 2005, 330, 753. [CrossRef]

52. Fedele, P.; Orlando, L.; Schiavone, P.; Quaranta, A.; Lapolla, A.M.; De Pasquale, M.; Ardizzone, A.; Bria, E.; Sperduti, I.; Calvani, N.; et al. BMI variation increases recurrence risk in women with early-stage breast cancer. Future Oncol. 2014, 10, $2459-2468$. [CrossRef] [PubMed]

53. Playdon, M.C.; Bracken, M.B.; Sanft, T.B.; Ligibel, J.A.; Harrigan, M.; Irwin, M.L. Weight Gain After Breast Cancer Diagnosis and All-Cause Mortality: Systematic Review and Meta-Analysis. J. Natl. Cancer Inst. 2015, 107, djv275. [CrossRef]

54. Engin, A. Obesity-associated Breast Cancer: Analysis of risk factors. Adv. Exp. Med. Biol. 2017, 960, 571-606. [CrossRef]

55. Camoriano, J.K.; Loprinzi, C.L.; Ingle, J.N.; Therneau, T.M.; Krook, J.E.; Veeder, M.H. Weight change in women treated with adjuvant therapy or observed following mastectomy for node-positive breast cancer. J. Clin. Oncol. 1990, 8, 1327-1334. [CrossRef] [PubMed]

56. Gandhi, A.; Copson, E.; Eccles, D.; Durcan, L.; Howell, A.; Morris, J.; Howell, S.; McDiarmid, S.; Sellers, K.; Gareth Evans, D.; et al. Predictors of weight gain in a cohort of premenopausal early breast cancer patients receiving chemotherapy. Breast 2019, 45, 1-6. [CrossRef]

57. Vance, V.; Mourtzakis, M.; McCargar, L.; Hanning, R. Weight gain in breast cancer survivors: Prevalence, pattern and health consequences. Obes. Rev. 2011, 12, 282-294. [CrossRef]

58. Anwar, S.L.; Cahyono, R.; Prabowo, D.; Avanti, W.S.; Choridah, L.; Dwianingsih, E.K.; Harahap, W.A.; Aryandono, T. Metabolic comorbidities and the association with risks of recurrent metastatic disease in breast cancer survivors. BMC Cancer 2021, 21, 590. [CrossRef]

59. Ewertz, M.; Land, L.H.; Dalton, S.O.; Cronin-Fenton, D.; Jensen, M.B. Influence of specific comorbidities on survival after early-stage breast cancer. Acta Oncol. 2018, 57, 129-134. [CrossRef]

60. Nechuta, S.; Lu, W.; Zheng, Y.; Cai, H.; Bao, P.P.; Gu, K.; Zheng, W.; Shu, X.O. Comorbidities and breast cancer survival: A report from the Shanghai Breast Cancer Survival Study. Breast Cancer Res. Treat. 2013, 139, 227-235. [CrossRef] [PubMed]

61. Zuniga, K.E.; Parma, D.L.; Muñoz, E.; Spaniol, M.; Wargovich, M.; Ramirez, A.G. Dietary intervention among breast cancer survivors increased adherence to a Mediterranean-style, anti-inflammatory dietary pattern: The Rx for Better Breast Health Randomized Controlled Trial. Breast Cancer Res. Treat. 2019, 173, 145-154. [CrossRef]

62. Park, H.A.; Lee, J.S.; Kuller, L.H. Underreporting of dietary intake by body mass index in premenopausal women participating in the Healthy Women Study. Nutr. Res. Pract. 2007, 1, 231-236. [CrossRef] [PubMed]

63. Johansson, G.; Wikman, Å.; Åhrén, A.-M.; Hallmans, G.; Johansson, I. Underreporting of energy intake in repeated 24-hour recalls related to gender, age, weight status, day of interview, educational level, reported food intake, smoking habits and area of living. Public Health Nutr. 2001, 4, 919-927. [CrossRef] [PubMed]

64. Singh, K.P.; Kober, K.M.; Ernst, B.; Sachdev, J.; Brewer, M.; Zhu, Q.; Gu, H.; Melisko, M.; Paul, S.M.; Cooper, B.A.; et al. Multiple Gastrointestinal Symptoms Are Associated With Chemotherapy-Induced Nausea in Patients with Breast Cancer. Cancer Nurs. 2021, in press. [CrossRef]

65. Naito, Y.; Kai, Y.; Ishikawa, T.; Fujita, T.; Uehara, K.; Doihara, H.; Tokunaga, S.; Shimokawa, M.; Ito, Y.; Saeki, T. Chemotherapyinduced nausea and vomiting in patients with breast cancer: A prospective cohort study. Breast Cancer 2020, 27, 122-128. [CrossRef] 